\title{
中国古籍与生物多样性保护 ${ }^{*}$ \\ 卢安奎 刘 文 \\ (哈尔滨市委党校哲学教研部, 哈尔滨 150080) \\ 李昳聪 \\ (黑龙江省广播电视大学生物化工系, 哈尔滨 150080) \\ 秋 实 \\ ( 东北林业大学人文学院，哈尔滨 150040)
}

摘 要 本文提出一种借助古代文献恢复自然生态系统的方法, 而中国古籍在这方面可以发挥巨大的 作用。生物多样性保护的技术性关键在于找到合适的生态系统, 而自然生态系统就是其中之一。中国 古籍,特别是中国医书、中国农书和中国方志的有关记载为寻找这种生态系统提供了大量的信息。因此 我们可以参考中国古籍, 使现存的复合生态系统逐步地接近自然生态系统, 从而达到生物多样性保护的 目的。

关键词 中国古籍,生物多样性保护,自然生态系统, 复合生态系统

Chinese classics and biodiversity conservation/Lu Ankui ${ }^{1)}$, Liu Wen ${ }^{1)}$, Li Yicong ${ }^{2)}$,Qiu Shi ${ }^{3)} / / \mathrm{CHI}^{-}$ NESE BIODIVERSITY. - $1997 \quad 5(4) 296 \sim 300$

The technological process to reconstruct ecosystem with the ancient books was introduced in this paper. Chinese classics will play an essential role in this aspect. To confirm what is the suitable ecosystem as the natural one is crucial for biodiversity conservation. Under the guidance of the Chinese classics, including medical literature , books of treatise on agriculture and district history, the artificial complex ecosystem in present can be gradually returned into the natural ecosystem similar to one in the ancient time. Thus we can reach the goal of the biodiversity conservation.

Key words Chinese classics, biodiversity conservation , natural ecosystem , complex ecosystem

Author's address 1) Department of Philosophy , Party School of Harbin Municipal Party Comittee , Harbin 150080

2 ) Department of Biochemical Engineering, Heilongjiang Broadcasting and TV University , Harbin 150080

3 ) The Humanities College , Northeast Forestry University , Harbin 150040

\section{1 引言}

生物多样性保护有种种措施，或易地保护，或就地保护，关键在于能恢复其生态系统，否则 无论采用什么措施最终都不会奏效。自然生态系统的人为改变最重要、最持久的方式就是农 业, 所以了解 农业摇篮” 或栽培植物的起源中心 ${ }^{[1]}$ 是十分必要的。学术界对中心的认识并不 一致 ${ }^{[2]}$,但却没有一个不承认中国中心的。既然中国为栽培植物的起源中心, 了解这个中心 生物的改变情况对生物多样性保护就很有意义。 


\section{2 背离自然生态系统之发展}

我们赖以生存的 复杂系统” ${ }^{[3]}$ 的 易损性 ${ }^{[4]}$ 之表现形态是生物多样性的丧失, 其根源是 由于人类的活动目的长期以来是背离生态系统的, 或者说满足人类发展长期以来是以生态系 统的破坏为代价的。

我国最早的诗歌总集《诗经》中的《诗. 商. 颂. 殷武》所记述的就是这样的事实 :

陟彼景山，(登到那个景山上，)

松柏丸丸。(松柏树干直又长。)

是断是迁，(于是锯断又运走，)

方斫是虔。( 于是斫平把树放。)

松桷有梴，(长的松木做屋椽，)

旅楹有闲，(长柏陈列做柱梁，)

寝成孔安。( 寝庙建成王安康。 $)^{[5]}$

砍伐山林建殿堂庙宇的记述很多, 唐代杜牧写 蜀山兀, 阿房出”便是其中的一例。事实上, 殿 堂庙宇只是人类住区发展的一个阶段、一个方面而已;当出现了文明曙光的时候，人与自然的 对立便确定了下来。很多文字中关于 村” 所表达的意思与汉文中的 村” 字是类同的 ,都是以 植被特别是森林的破坏为前提的。

人类出于独特的价值观念，对自然生态系统进行了改造，对自然资源进行了配置和创造； 先民们发展农业, 发明了医药……, 并在特定的区域内改造自然生态系统, 直到把它搞得面目 全非，适得其反，令人担忧。美国国家科学院全球变化委员会委员、奥地利国际应用系统分析 研究所 生物圈长期持续发展项目” 主持人威廉 $\mathrm{C}$ 克拉克针对人类对全球性变化的管理问题 十分焦虑, 他说“: 未来几十年面临的一项重大挑战, 就是学会怎样调节人类活动与地球环境 之间的长期而大规模的相互作用，以期持续改进人类生存和幸福的前景。调控与预测不是一 回事, 也与理论知识不同，因为虽然由于存在巨大的不确定性和十足的无知，而使详细的预测 变得不切实际, 管理即调控还是可以改进的。一个关键问题是 :我们究竟是否在切实对环境变 化管理, 如果回答是肯定的, 那就要问——针对不同情况采取什么样的社会行动最为有 效。” ${ }^{[6]}$ 这确实是一个重要的问题。而要解决这一问题, 则需要我们了解其逐步变化的过程。

中国几千年积累的大量典籍中, 有不少记载可以使我们了解当时的生态系统情况, 特别是 中国的医书、农书和方志, 可以使我们认识到生态系统的改变过程, 因而为生态系统的恢复提 供历史依据，从而为生物多样性保护工作提供有益的资料。

\section{3}

\section{中国古籍对生物多样性保护的一般价值}

中国是世界四大文明古国之一,但中国与其它文明古国不同,它是唯一延续到今天的国 家。尽管历经坎坷,曾几次被异族统治, 但是所有的征服者都毫无例外地被这种文明所征服。 德国大哲学家黑格尔曾惊奇地发现，在世界历史中，唯有黄河、长江流域的那个中华帝国从 3000 年前一直连续存在到今天。维持这种文明的因素是多方面的, 但其根本原因却在于它有 雄厚的生态系统为基础。也许印加帝国因干旱而消亡的事实可以从反面说明中华文明持续存 在的原因。

中国古籍，包括甲骨文在内，对德康多尔( A de Condole)、瓦维洛夫 ( N I Vavilov) 等人所谓 栽培植物起源中心之一的中国中心 ${ }^{[1,2]}$ 的物种和生态状况有过大量的记录。例如卜辞曾记录 
了当时捕获猎物的种类和数量，如：

“丙戌卜丁亥王鹿, 口。允口三百又四十八。”

“壬申卜 $\times$ 贞圃。鹿, 丙子⿴ 鹿, 允口二百又九, 一×。”

“获鹿二百。”

“( 缺) 田稌 [往来亡] 灾, 幻御。 $\times \times$ 二百五十 $\times$,雉二。”

“丁卯[卜贞王] 狩正 $\times$ 口获鹿百六十二, $\square$ 百十四, 豕十, 兔一。”

“ $\times$ ×王卜贞田稌往 [ 来亡灾 ,]王固,曰吉,幻御。[获] $\times$ 百四十八,兔二。”

“狩获—鹿五十又六。”

“获狐四十一。”

“获狐二十五。”[7]

郭沫若先生曾将其所见加以总结, 发现被猎的兽类, 无论是被获的次数还是每次被获的匹 数, 都以鹿为首位。他将一百八十六条田猎中各种被获的兽类、每类被获的次数以及被获匹数 的最高纪录整理成如下表：

\begin{tabular}{|c|c|c|}
\hline 被获物 & 次数 & 最高纪录匹数 \\
\hline 鹿 & 二四 & 三四八 \\
\hline 狐 & -- & 四一 \\
\hline 羊 & 八 & ( 无记录) \\
\hline 马 & 六 & 六 \\
\hline 豕 & $\equiv$ & - 一 \\
\hline 兔 & 二 & -0 \\
\hline 雉 & 二 & 六 \\
\hline
\end{tabular}

当然, 被获物有的并不是十分肯定为何物的。如 狐” 是郭沫若的见解“, 狼” 是罗振玉的见解， 而原文为 犸” “; 兔”与莟” 在甲骨文中又极易混淆。郭沫若把卜辞中的有关条目整理为渔 猎、牧畜、农业、工艺、贸易,使我们从一个侧面了解了“中国中心”的动植物种类及数量。当 然, 卜辞的记录有其特殊旨意, 而郭沫若的兴趣在于体制文化, 都与生物多样性有距离, 但是这 些记录对于恢复 中国中心” 都是极有价值的。卜辞中还有关于气象与农时的内容, 当时的巫 占卜风、雨、雷、电、阴、晴、晦、雺、雾、雪、虹霓, 而且区分细淢, 雨有纵雨、大雨、中雨、小雨、多 雨、少雨、延雨、霖、䌺雨、等, 并且有来雨的方向; 侑大掫风、大风、小风、延风, 亦有风来的 方向和四方风名各自的特性 ;雪有 某时雪” “今日雪” “翌日雪” “中日雪” 和 雨雪” 等等。 这些对了解当时的生态条件无疑都是有积极意义的。

反映或记录 中国中心”的中国古籍很多，中国地理著作、中国农书、中国医书、中国方志 等在恢复 中国中心” 的生物多样性方面的价值是显然的。但中国的词书，甚至文艺作品也不 可忽视。例如中国最早的词书《尔雅》中就有《释天》、《释地》、《释丘》、《释山》、《释水》、《释 虫》、《释鱼》、《释鸟》、《释兽》、《释畜》、《释草》、《释木》等专篇; 后来三国魏时又编《广雅》也 有类似的专篇并补充以前之不足。

值得注意的是, 被尊为百经之首的《易经》作为中国哲学之始肇事于天人关系, 缘此产生 了中国特有的风水，它用于宅院的选址上实际就是 ecology 即生态学，而这个词源于希腊文 oikos ,原意 家” 和 住处”。所以, 中国古籍在恢复 中国中心” 的生态系统具备相当的参考价 值。 


\section{4 中国医书 ${ }^{(1)}$ 对生物多样性保护的价值 $*$}

汉代《神农本草经》是现存最早的药物学专著,成书于公元一到二世纪。这本书载药 365 种, 其中植物药 252 种, 动物药 67 种, 矿物药 46 种。这本书中的药材来源地域已相当广泛, 既 超越了所谓 中国中心”,也超越了中国现今的版图。

南北朝《神农本草经集注》大约在公元 502 年编成, 载药 730 种, 按草、木、米食、虫兽、玉 石、果菜和有名未用等分为七类,并且对药物的性味、产地、采集、形态和鉴别等方面均有论述。

唐代《新修本草》于公元 657 年开始编修,659 年完成, 载药 844 种, 分药图、图经、本草三 部分,并详述了药物性味、产地、功效和主治。

隋唐《千金要方》和《千金翼方》分别在公元 652 年和 681 年完成,共载药 873 种,按玉石、 草、木、人兽、虫鱼、果、菜、米、谷进行分类,对 233 种植物药的采集时节作了扼要说明,在药 出州土”一栏中详列各地出产的药物。

宋代《经史证类备急本草》1083 年完成, 后又经多人分别于 1108 年、1116 年、1159 年修 订, 载药 1746 种。

明代《本草纲目》以上书为蓝本, 1578 年完成, 载药 1892 种, 附动植物插图 1162 幅。记载 植物药 1094 种, 动物药 445 种。首标正名为纲, 再行分目, 如标桑为纲, 而列桑白皮、桑皮中白 汁、桑椹、桑枝、桑耳、桑花、桑寄生为目。对每种药的性味、产地、形态、采集方法均有详细说 明。

以上我们简单地罗列了中国药物学的经典, 不难看出借助于这些经典可以确知所记载的 动植物或菌类曾生活过的区域或时间。由于药物学所载生物多为野生,所以为我们从一个方 面提供了自然生态系统的状况。

\section{5 中国农书对生物多样性保护的价值}

据专家统计，中国古代农书 (包括现存的和已经散佚的) 共有 376 种之多。这些书为我们 提供了被栽培的植物和被驯化的动物的种类和培育情况, 使我们得以窥见古代人为生态系统; 另外也提供了部分野生植物、动物的情况, 如野菜、杂草、蝗虫和其它害虫等。这实际上是自然 生态系统对人工生态系统的合作与补充。农书中最具规模者为：

北魏《齐民要术》,为大约公元 $533 \sim 544$ 年的著作；

元《王祯农书》约 1313 年成书 ;

明《农政全书》1639 年成书。

这些书的差异可以在不同程度上给出 中国中心”生态系统的变化情况。

\section{6 中国方志对生物多样性保护的价值}

据 1958 年朱士嘉《中国地方志综录》增订本统计, 全国地方志共 7413 种, 109 143 卷, 其中 既有全国性的总志也有地方性的州郡府县志。

唐《元和郡县志》是现存最早、篇幅较完整的全国性总志,记事以唐宪宗元和八年即公元 813 年为限, 以当时的四十七节镇为标准, 分镇记载府州县的范围、道里、山川、沿革、户口、贡 赋、物产、名胜古迹等项。 
宋《太平寰宇记》,体例因袭前书，从东京开封写起，继而分卷记述各州、郡的沿革、境界、 户数、风俗、姓氏、人物、土产; 各州沿革, 追溯到远古, 对其区域、交通均有说明, 而在户数栏内， 又分别列出唐代户数与宋代户数;对各州风俗介绍价值很大。如卷一百十四言潭州风俗, 人多 纯朴，火耕水耨，食鱼稻，以渔猎伐山为业，不忧冻饿，亦少千金之家。

元《大元大一统志》,1286 年开始编写, 1294 年成书, 后又于 1303 年修订, 今只有残本。

地方性的方志数量相当可观现存最早的为东晋常璩的《华阳国志》, 记述了今汉中、四川 和云贵的风土人物; 宋代的方志猛增, 有四五百种, 现存三十余部; 明代县志、府志、省通志、两 省合编的总志，以及乡志、镇志等特别多，仅现存的就有 770 种、10 087 卷, 而浙江宁波天一阁 原藏省、府、州、县志 435 种，现存 268 种;清代达到极盛时期，在各省区设立修志局，由学正监 督其事，另外各地还编修关、卫、屯、所、镇、乡、山、水、湖、海、堤、塘、园、楼、亭、寺、庙、庵、塔、 祠、桥、书院等志，方志达 5800 种之多。

无论是全国性的总志还是区域性的方志，都会给我们提供 中国中心”的历史情况，特别 是其地理位置方面更加详细的信息。

\section{7 结语}

时间具有不可重复性, 即过去与未来之间并不存在经典物理学所谓的对称性, 所以要完全 恢复” 某种事物是根本不可能的。但是, 我们却可以创造类似的条件, 在某种程度上让它再 现。

生态系统和物种多样性的存在 ,比无生命的系统发展更具有方向性和动态性。据专家们 研究,在中国这片土地上,气候的变化相当之大。所以我们不能死板地依据古籍,如医书、农书 或方志中所确定的物种去再现历史上的生态系统, 也不能简单地平移,如中原曾是亚热带气候 带, 我们不能把古籍中所记载的有关中原之生态或物种简单地用到今天的 亚热带”, 而是需 要一种创造性的重建。

另外，古籍由于受时代的限制，记述得不一定可靠，未必正确。所以还要作些训诂考据工 作，以图再现当时的真实情况。唯有下了这番功夫，古籍才能成为恢复昔日生态系统的根据， 才能在生物多样性保护中发挥出应有的作用。

\section{参 考 文 献}

1 Vavilov N I. The origin, variation, immunity and breeding of cultivated plants (Selected writings). Chronica Botanica. 1951,13

2 Hutterer K L. Some viewpoints on the origin and evolution of crops. History of Southeast Asian Agriculture

3 United Nations University. The science and practice of complexity. Tokyo : United Nations University , 1985

4 Timmerman P. Vulnerability, resilience and the collapse of society. Research Monograph, 1981, 1

5 姜胜章编校.《诗经》. 长沙 湖南出版社, 1993,758

6 威廉 $\mathrm{C}$ 克拉克. 全球性变化中的人类生态学. 国际社会科学杂志一一协调社会圈与生物圈专集 (中文 版 ) , 1990,7(3) $23 \sim 55$

7 郭沫若全集. 历史编(第一卷). 北京: 人民出版社 ,1982，198～199 